\title{
A ESTREITA RELAÇÃO ENTRE A MICROBIOTA RUMINAL E OS ADITIVOS MICROBIANOS
}

Flávia Oliveira Abrão Pessoa ${ }^{1 *}$; Eduardo Robson Duarte ${ }^{2}$; Moisés Sena Pessoa ${ }^{3}$; Vera Lúcia dos Santos ${ }^{2}$; Luis Henrique Curcino Batista ${ }^{4}$, Thiago Dias Silva ${ }^{4}$, Ronaildo Fabino Neto ${ }^{4}$; Norberto Mário Rodriguez ${ }^{2}$

\footnotetext{
${ }^{1}$ Docente do Instituto Federal Goiano, Campus Ceres. ${ }^{2}$ Docentes da Universidade Federal de Minas Gerais. ${ }^{3}$ Doutorando em Zootecnia pela Universidade Federal de Goiás, Goiânia. ${ }^{4}$ Graduando em Zootecnia do Instituto Federal Goiano, Campus Ceres. E-mail: flavia.abrao@ifgoiano.edu.br
}

\section{RESUMO}

Objetiva-se com a presente revisão abordar aspectos relacionados a microbiota ruminal, especialmente de animais criados em sistemas extensivos e, relacionar mecanismos modulatórios de aditivos microbianos com a população de microrganismos e parâmetros ruminais. Diferentes moduladores da microbiota ruminal têm sido estudados a fim de melhorar a atividade microbiana no rúmen. Alimentação com prebióticos, probióticos ou ambos; e suplementação com culturas de exclusão competitiva tem sido utilizadas para limitar a proliferação de $E$. coli 0157 em animais de produção que atuam como potenciais reservatórios desta cepa bacteriana. Também é sabido que culturas microbianas vivas dos fungos exógenos Aspergillus oryzae e Saccharomyces cerevisiae e os seus respectivos extratos têm sido utilizados como suplementos alimentares na dieta dos animais, e que estes podem melhorar a produtividade de ruminantes em aproximadamente sete a oito por cento. Foi constatado que aditivo constituído de Saccharomyces cerevisiae tende a estimular o crescimento de bactérias celulolíticas no rúmen de cordeiros recém-nascidos. Contudo, apesar de vários relatos positivos, diferentes entraves ainda ocorrem no campo para o emprego de aditivos na produção animal. Resultados diversos são encontrados, muitas vezes justificados pela condição do animal, seleção e viabilidade de cepas do produto. Futuros estudos tornam-se necessários para elucidar a melhor forma de administração e aplicabilidade, especialmente para animais condicionados ao clima tropical, com escassez de chuvas e alimentos de baixo valor nutricional.

Palavras-chave: bactéria, leveduras, probióticos, rúmen.

\section{THE STRONG RELATIONSHIP BETWEEN RUMINAL MICROBIOTE AND MICROBIAL ADDITIVES}

\begin{abstract}
The objective of this review is to discuss aspects related to ruminal microbiota, especially of animals raised in extensive systems, and to relate modulatory mechanisms of microbial additives with the microorganism population and ruminal parameters. Different modulators of the ruminal microbiota have been studied in order to improve the microbial activity in the rumen. Feeding with prebiotics, probiotics or both; and supplementation with competitive exclusion cultures have been used to limit the proliferation of $E$. coli 0157 in production animals that act as potential reservoirs of this bacterial strain. It is also known that live microbial cultures of the exogenous fungi Aspergillus oryzae and Saccharomyces cerevisiae and their extracts have been used as dietary supplements in the animal diet, and that these can improve the productivity of ruminants by approximately seven to eight percent. It was found that the additive constituted of Saccharomyces cerevisiae tends to stimulate the growth of cellulolytic bacteria in the rumen of newborn lambs. However, despite several positive reports, different barriers still occur in the field
\end{abstract}


for the use of additives in animal production. Several results are found, often justified by the animal condition, selection and viability of product strains. Future studies are needed to elucidate the best form of administration and applicability, especially for animals adapted to the tropical climate, with lack rainfall and feeds of low nutritional value.

Keywors: Bacteria, yeasts, probiotics, rumen. 


\section{INTRODUÇÃO}

Com o melhoramento no manejo nutricional de ruminantes nos últimos 30 anos, tem-se observado aumento gradativo nos índices de produção de carne e leite (Nooraee et al., 2010). Atualmente, a bovinocultura é responsável pelo abastecimento da maior parte da demanda mundial de proteína animal. A carne e o leite bovinos possuem participação significativa na economia nacional, representando $8,4 \%$ do Produto Interno Bruto (PIB) brasileiro. Aproximadamente $25 \%$ do território brasileiro é formado por pastagens, tal área vem crescendo moderadamente. Já o rebanho bovino do Brasil é constituído, de aproximadamente, 208 milhões de cabeças, com a produção anual de 59,6 milhões de toneladas de carne e 33,3 bilhões de litros de leite. Em Minas Gerais, no ano de 2013 os produtos de origem animal representaram 43,3\% do valor bruto da produção agropecuária mineira. Os níveis médios de produtividade ainda são baixos e os pastos são insuficientes para alimentar todo o rebanho. A demanda potencial interna e externa por esses produtores é grande, exigindo do setor altas taxas de crescimento a cada ano (Abpa, 2015; Faemg, 2013; Seab, 2014).

A notável capacidade de produção proteica nos ruminantes é atribuída ao sistema de préestômagos, o qual alberga complexo ecossistema microbiano. Como os alimentos fibrosos são à base da alimentação dos ruminantes, esse ecossistema tem importância única, por ser responsável pela degradação da fibra vegetal, digerindo os polímeros da parede celular (Stewart, 1994). Essa interação simbiótica pode suprir os ruminantes quanto aos requisitos energéticos, proteicos e vitamínicos, contribuindo para o crescimento, produção e reprodução (Oliveira et al., 2007).

Diferentes moduladores (ionóforos, própolis, óleos essenciais, simbióticos...) da microbiota ruminal têm sido estudados a fim de melhorar a atividade microbiana no rúmen (Nagaraja et al., 1997). Entretanto, evidências científicas sobre os efeitos causados com o uso desses aditivos ainda não são conclusivas (Nooraee et al., 2010).

Estudos têm relatado efeitos positivos da dieta suplementada com culturas de Saccharomyces cerevisiae no processo de fermentação ruminal e na produtividade de ruminantes (Wallace, 1994; Wallace; Newbold, 1995; Stella et al., 1997). Em contrapartida, outras pesquisas não reportam efeitos benéficos significativos sobre esses mesmos parâmetros (Gattass et al., 2008).

Apesar dos inúmeros trabalhos utilizando cepas de $S$. cerevisiae e extratos do fungo Aspergillus oryzae ou aditivos microbianos em dietas de ruminantes, os resultados são controversos e a maioria é restrita a esses dois fungos. Poucos estudos avaliam a utilização de microrganismos naturalmente encontrados no trato gastrointestinal de ruminantes como aditivos microbianos.

Em regiões de clima semiárido, observa-se a escassez de forrageiras de boa qualidade ao longo de todo o ano. Este fato pode ser atribuído ao menor índice pluviométrico e ao maior período de déficit hídrico. A quantidade de alimento disponível é comprometida, assim como a qualidade das pastagens persistentes à seca. A redução de digestibilidade dos tecidos vegetais ocorre por causa do processo fisiológico de lignificação da parede celular (Gerônimo, 2011).

As pastagens tropicais apresentam-se lignificadas e com menor degradabilidade ruminal na maior parte do ano, limitando o aproveitamento de nutrientes pelos ruminantes, reduzindo o desempenho animal, principalmente no período seco. Contudo, graças às características como tolerância à seca e a solos de média e baixa fertilidade, assim como boa produção de massa vegetal, o gênero Brachiaria tem sido amplamente difundido como forrageira em regiões tropicais (Zimmer; Euclides, 2000). Dessa forma, evidencia-se a relevância de otimizar a degradação dessa forragem, uma vez que esta é uma das principais fontes de alimento para bovinos criados em pastagens no Brasil. 
Isolados fúngicos provenientes da microbiota autóctone do rúmen com atividade superior de enzimas celulolíticas e xilanolíticas, importantes na degradação da parede celular vegetal e adaptados às condições tropicais, poderão ser suplementados como aditivos microbianos ou probióticos para bezerros, principalmente após o desmame, e para as demais categorias de bovinos antes do período da seca. Essa suplementação poderá reduzir o período de adaptação para digestão de forragens de baixos valores nutricionais, presentes no período de seca em nosso país, reduzindo a perda de peso e aumentando a produtividade desses animais. A detecção de microrganismos com potencial utilização para aditivos permitirá aumento de produtos no mercado de aditivos microbianos adaptados às condições tropicais e semiáridas.

Objetiva-se com a presente revisão abordar aspectos relacionados a microbiota ruminal, especialmente de animais criados em sistemas extensivos e, relacionar mecanismos modulatórios de aditivos microbianos com a população de microrganismos do rúmen e com parâmetros ruminais como $\mathrm{pH}$, ácidos graxos voláteis (AGV's), dentre outros.

\section{MICROBIOTA RUMINAL}

$\mathrm{O}$ rúmen pode ser comparado a uma câmara fermentativa, com um ambiente anaeróbio estrito, temperatura entre 38 e $42^{\circ} \mathrm{C}$, favorável ao crescimento de microrganismos mesófilos e pH entre seis e sete. Os ácidos produzidos durante a fermentação são prontamente tamponados pelo bicarbonato e fosfato presentes na saliva. O ambiente ruminal adequado favorece a pressão da microbiota autóctone sobre os microrganismos do solo, água e alimentos ingeridos a todo instante pelos ruminantes (Ruiz-Lacaz et al., 1992).

No interior do rúmen, há uma complexa mistura de fragmentos alimentares e de microrganismos. A população microbiana no rúmen geralmente está distribuída da seguinte forma: bactérias $\left(10^{10} \cdot \mathrm{mL}^{-1}\right)$, protozoários ciliados $\left(10^{6} \cdot \mathrm{mL}^{-1}\right)$, fungos anaeróbios estritos $\left(10^{6} \cdot \mathrm{mL}^{-1}\right)$, micoplasmas (indeterminado), fungos anaeróbios facultativos $\left(10^{4} \cdot \mathrm{mL}^{-1}\right)$, enterobactérias $\left(10^{6} \cdot \mathrm{mL}^{-}\right.$ $\left.{ }^{1}\right)$ e bacteriófagos $\left(10^{8} \cdot \mathrm{mL}^{-1}\right)$, os quais estabelecem entre si diversas interações positivas ou negativas (Abrão et al., 2014; Kamra, 2005; Ruiz-Lacaz et al., 1992). O sinergismo in vivo entre espécies resulta, frequentemente, de uma sucessão ecológica. Geralmente, é observada a colonização inicial com uma espécie que libera um produto que é utilizado como substrato por outras espécies (Flint, 1994).

Os microrganismos habitantes do rúmen possuem relação de simbiose com o hospedeiro. A microbiota ruminal atua sinergicamente para bioconverter substâncias menos aproveitáveis como a celulose, a hemicelulose e a amônia em compostos utilizáveis pelo ruminante, como os ácidos graxos voláteis (AGV's), os aminoácidos (aa's), as vitaminas e outras substâncias necessárias ao crescimento e à produção de carne, leite e lã (Kamra, 2005; Oliveira et al., 2007).

As populações microbianas podem sofrer flutuações de acordo com as estações do ano e isso pode ser associado aos níveis de AGV's e amônia $\left(\mathrm{NH}_{3}\right)$, disponibilizados no rúmen (Martillotti et al., 1994). Grandes populações de bactérias e fungos têm sido observadas quando altas concentrações de $\mathrm{NH}_{3}$ e AGV's estão presentes no rúmen. $\mathrm{O}$ estabelecimento e a manutenção da estabilidade das populações microbianas no rúmen são dependentes principalmente da dieta, da qualidade da alimentação e da sua frequência de distribuição, bem como das interações microbianas (Dehority, 1998).

Esse ecossistema é considerado dinâmico, pois pode ser fisiologicamente alterado em função da adaptação e da composição da dieta disponibilizada ao animal, embora também seja considerado estável, por possuir uma população microbiana bem estabelecida, capaz de produzir proteínas de alto valor nutricional a partir de compostos de qualidade inferior. A microbiota autóctone do rúmen foi selecionada e adaptada para sobreviver a determinadas flutuações presentes no ambiente ruminal. Microrganismos incapazes de sobreviver a essas variações são eliminados e desaparecem (Kamra, 2005). 


\subsection{Bactérias anaeróbias do rúmen}

Onze grupos de bactérias anaeróbias estritas podem ser encontrados no rúmen e eles estão classificados em função do principal substrato que utilizam ou produtos liberados. Esses grupos são atualmente descritos como celulolíticos, hemicelulolíticos, pectinolíticos, amilolíticos, ureolíticos, sacarolíticos, acetolíticos, proteolíticos, lipolíticos, amoniagênicos e metanogênicos (Ruiz-Lacaz et al., 1992).

Observa-se grande variabilidade genética entre amostras de bactérias ruminais de mesma espécie. Estudos revelaram que essas amostras podem sofrer altas taxas de mutações, mesmo mantidas em coleções em laboratórios (Flint, 1994).

Dentre os principais gêneros destacam-se: Fibrobacter, Ruminococcus, Butyrivibrio, Succinomonas, Selenomonas, Succinivibrio, Eubacterium, Lactobacillus, Bacteroides, Prevotella (Russel; Rychlik, 2001).

Dentre os fermentadores de carboidratos estruturais, as espécies Ruminococcus albus $e$ Ruminococcus flavefaciens parecem ser mais eficientes, liberando como principal subproduto o acetato (Arcuri et al., 2011). Amido e outros carboidratos não estruturais são utilizados por espécies como Megasphaera elsdenii, Selenomonas ruminantium e Streptococcus bovis (anaeróbia facultativa). Essas espécies, por sua vez, liberam no ambiente ruminal subprodutos como propionato, butirato, hidrogênio $\left(\mathrm{H}_{2}\right)$ e, lactato (Arcuri et al., 2011).

Sabe-se que a atividade ureolítica de bactérias, como a Helicobacter pylori, leva à conversão rápida de ureia em amônia no rúmen, resultando em alguns casos, em possível toxicidade aos animais, excreção excessiva de amônia para o ambiente e baixa utilização de nitrogênio (Zhao et al., 2015).

Já as bactérias metanogênicas sintetizam metano $\left(\mathrm{CH}_{4}\right)$, a partir de gás carbônico $\left(\mathrm{CO}_{2}\right)$ e $\mathrm{H}_{2}$, promovendo a redução da concentração de hidrogênio e assegurando a continuação da degradação de fibras e a fermentação ruminal com o controle do pH (Ruiz-lacaz et al., 1992). Há relatos da colonização de Archea no rúmen não desenvolvido de cordeiros antes mesmo do início da ingestão de sólidos (Morvan et al., 1994; Abecia et al., 2013).

Tipicamente, a população metanogênica compreende menos que três por cento da microbiota procariota do rúmen, e em contraste com outras bactérias do rúmen, a maioria das metanogênicas ruminais parecem pertencer a apenas três principais gêneros, ou seja, Methanobrevibacter (62\% das metanogênicas), Methanomicrobium (15\%) e Methanoplasmatales (16\%) (Paul et al., 2012). A minoria restante pertence aos gêneros Methanimicrococcus, Methanosarcina e Methanobacterium (Belanche et al., 2014).

\subsection{Enterobactérias encontradas no ambiente ruminal}

Frequentemente também tem sido relatado a prevalência de enterobactérias em ruminantes que, atuam como reservatórios para esses microrganismos zoonóticos. De acordo com Chaucheyras-Durand et al. (2006) o trato gastrointestinal de ruminantes é o principal reservatório da Escherichia coli enterohemorrágica (EHEC), bactéria responsável por infecções de origem alimentar nos seres humanos que podem levar à doença renal grave.

Sabe-se que o tipo de carboidrato na dieta tem um efeito direto na concentração de $E$. coli no trato gastrointestinal de bovinos (Gilbert et al., 2005). Alimentação com prebióticos, probióticos ou ambos; e suplementação com culturas de exclusão competitiva tem sido utilizadas para limitar a proliferação de E. coli 0157 em animais que atuam como potenciais reservatórios (LeJeune; Wetzel, 2007). Estudos demonstraram que a administração de bactérias probióticas antes do abate dos animais pode reduzir significativamente a introdução de E.coli na cadeia alimentar humana (Duncan et al., 1999).

Além de $E$. coli, são encontratadas no conteúdo ruminal os gêneros Shigella, Salmonella, Klebsiella, Proteus, Morganella, Yersinia, Enterobacter, Citrobacter e Serratia. Ambos fermentam 
glicose, reduzem os nitratos a nitritos e são, produtoras de endotoxinas. Algumas são capazes de produzir a enzima lactase, diferindo-as em 2 subgrupos: Lac + as produtoras e Lac - não produtoras (Stewart, 1988; Pessoa, 2012).

Pouco se sabe sobre a colonização do ambiente ruminal por esses microrganismos e seu papel no rúmen ou interferência na saúde dos animais de produção. Tkalcic et al. (2000) avaliaram a interferência da dieta sobre a população de E. coli 0157:H7 no rúmen de bezerros. Foi relatado que a população de Enterobacteriacea não diferiu significativamente entre animais que receberam dietas com altos teores de concentrado daqueles alimentados com alta porcentagem de volumoso. Entretanto, Callaway et al. (2009) numa revisão bibliográfica dos últimos 10 anos, relataram que as populações totais de $E$. coli foram maiores no rúmen de bovinos alimentados com maiores teores de grão do que àqueles submetidos à pasto.

Foram observados bacilos Gram-negativos do grupo das Enterobacteriacea no rúmen de bovinos leiteiros alimentados com forragens tropicais nas concentrações médias de $8,4 \times 10^{6}$ e 1,4 x $10^{5}$ Unidades Formadoras de Colônia (UFC) por mililitro ( $\mathrm{mL}$ ), para novilhas e vacas, respectivamente (Freitas et al., 2014).

Em função do potencial patogênico desses microrganimos, alguns trabalhos têm utilizado fitoquímicos como o tanino na alimentação animal para o controle de enterobactérias. Esses compostos são encontrados naturalmente em determinadas forragens, que podem ser utilizadas em pequenas quantidades para reduzir a população de $E$. coli, sem comprometer negativamente a produção animal (Berard et al., 2009).

Outra alternativa para redução na população de enterobactérias que tem sido apontada é o fornecimento de clorato de sódio ao animal 24 horas ( $h$ ) antes ao abate. Esse composto reduz a prevalência desses organismos sem alterar o padrão fermentativo do rúmen (Callaway et al., 2004). A enzima intracelular bacteriana, nitrato redutase, não diferencia o nitrato desse análogo, clorato, que é reduzido em clorito no citoplasma; ocorrendo assim acúmulo de clorito dentro da célula e morte dessas bactérias (Stewart, 1988).

\subsection{Protozoários ruminais}

Os protozoários, por sua vez, possuem considerável atividade celulolítica e, podem representar $2 \%$ de peso do conteúdo ruminal, $40 \%$ do nitrogênio $(N)$ total e $60 \%$ do produto final da fermentação. Dentre os principais gêneros destacam-se: Dasytricha, Isotricha, Charonina, Entodinium, Diplodinium, Eodinium, Epidinium, Polyplastron e Diploplastron (Franzolin; Dehority, 1996; Arcuri et al., 2011).

A faixa de pH ótima para o ciclo de vida dos protozoários ruminais está entre 6,0 e 7,0. Os protozoários são inibidos em pH inferior a 5,5 e morrem quando o pH é igual ou menor a 4,5. O pH é o fator isolado mais importante no controle do número de protozoários ruminais (Franzolin; Dehority, 1996).

No ambiente ruminal esses microrganismos concomitantemente estão envolvidos com canibalismo entre indivíduos. Promovem predação bacteriana, engolfamento de grânulos de amido. Apresentam elevada atividade metabólica, devido a presença da organela hidrogenossoma, que está relacionada com a produção de hidrogênio e relação direta com os organismos metanogênicos. Estima-se que entre $9 \%$ e $25 \%$ das metanogênicas do rúmen estão em associação com os protozoários (Martilene; D’Agosto, 2008; Arcuri et al., 2011; Belanche et al., 2014).

A relevância dos protozoários no rúmen ainda é bastante controversa. Trabalhos apontam que ruminantes conseguem sobreviver sem esses organismos presentes no rúmen. Contudo, tem sido observado que animais faunados apresentam maior ganho de peso e digestibilidade superior, quando comparados com os defaunados. Quando o rúmen está defaunado e inoculado com uma única espécie, é possível determinar a ação de cada espécie na degradação dos vegetais. Um 
exemplo típico é o aumento da digestibilidade da matéria seca e da matéria orgânica, quando somente Polyplastron multivesiculatum está inoculado em um animal previamente defaunado (Ruiz-Lacaz et al., 1992).

Estudos mostram atividade de xilanases e carboximetilcelulases entre diferentes espécies de protozoários do rúmen. De acordo com Béra-Maillet et al. (2006), um conjunto de carboximetilcelulases e xilanases é produzido pelos grandes ciliados Polyplastron multivesiculatum e Eudiplodinium maggii, entretanto Entodinium sp. não é apontado como produtor dessas enzimas.

\subsection{Fungos anaeróbios facultativos encontrados no fluido ruminal}

Fungos anaeróbios facultativos são aqueles capazes de utilizar o oxigênio ou um componente orgânico como aceptor final de elétrons. Essa característica é atributo valioso, uma vez que permite a esses fungos sobreviver em vários ambientes (Madingan et al., 2010).

Pouca importância tem sido dada a esse grupo de microrganismos no rúmen. Contudo, recentes pesquisas têm analisado como esses organismos interferem no processo fermentativo e qual o papel destes no metabolismo de ruminantes. Sabe-se que esses fungos chegam no ambiente ruminal a partir da alimentação, com arraçoamento, pastejo extensivo e ingestão de água (Davies et al., 1993).

As fezes também podem servir como rota de transferência de fungos entre os herbívoros. Apesar de não ocorrer coprofagia entre ruminantes, acidentalmente pode haver ingestão de fezes frescas ou secas contaminadas com estruturas de resistência e aerotolerantes (Davies et al., 1993).

Estudos têm demonstrado variação na população de leveduras e fungos filamentosos no rúmen de bovinos de corte. Os gêneros Aspergillus, Onychocola, Trichophyton e Paecilomyces compõem a micobiota ruminal de vacas e bezerros de corte. Leveduras foram isoladas de aproximadamente $25 \%$ desses animais (Abrão, 2009). Estudos recentes mostraram que a média de UFC. $\mathrm{mL}^{-1}$ de fungos micelianos no líquido ruminal de vacas e bezerros criados em pastagens de Brachiaria spp. durante o período seco foi de $2,61 \times 10^{4}$ e $3,26 \times 10^{3}$ (UFC. $\mathrm{mL}^{-1}$ ), respectivamente (Magalhães et al., 2010).

Oyeleke e Okusanmi (2008) estudaram a prevalência de fungos celulolíticos no fluido ruminal de cinco vacas, cinco ovelhas e cinco cabras e observaram maior proporção desses microrganismos nas amostras provenientes das vacas. Os gêneros Fusarium, Penicillium, Aspergillus e Mucor foram os mais prevalentes para as espécies de ruminantes avaliadas e apresentaram atividade celulolítica comprovada.

Almeida et al. (2014) corroboram com os trabalhos relacionados acima, e reportaram que o gênero Aspergillus foi o mais frequente no conteúdo ruminal de bovinos leiteiros alimentados com forragens tropicais e apresentou isolados com elevada atividade celulolítica. Foram ainda identificados os gêneros Gliocladium, Paecilomyces, Rhizophus e Scedosporium spp. no rúmen de vacas leiteiras (Almeida et al., 2014).

Em outro estudo, Abrão et al. (2011) relatam concentrações significativas da levedura Pichia membranifaciens no rúmen de caprinos de corte criados em pastagens tropicais. A levedura foi identificada pela primeira vez no ambiente ruminal e foi destacado o possível potencial na saúde e nutrição de ruminantes. Essa espécie apresenta capacidade de utilização de etanol, podendo indicar possível efeito benéfico, por reduzir perdas no processo de fermentação ruminal e melhorar o teor protéico.

A levedura Candida krusei, importante agente de micoses oportunistas em animais e humanos, foi relatada no rúmen de bovinos leiteiros criados no Norte de Minas Gerais. O papel ecológico ou patogênico dessa e outras leveduras deve ser considerado, buscando melhor produtividade e saúde de ruminantes (Almeida, 2009). 
Atualmente já são pesquisadas formas de inclusão de fungos na dieta de ruminantes visando efeito modulatório da microbiota do rúmen, nos processos fermentativos e consequentemente, melhoria sobre parâmetros produtivos (Lee et al., 2000; Noorae et al., 2010).

\subsection{Fungos anaeróbios estritos do rúmen}

Os fungos anaeróbios do rúmen são produtores de zoósporos e pertencem à classe dos Chytridiomycetos. Até o presente, esses são classificados na divisão Eumycota, subdivisão Mastigomicotina, classe Chytridiomycetos, ordem Neocallimastigales, família Neocallimasticacea e gêneros Caecomyces, Cyllamyces, Piromyces, Neocallimastix, Anaeromyces e Orpinomyces (Li et al., 1993; Ozkose et al., 2001).

São conhecidas 20 espécies nos seis gêneros de fungos anaeróbios do rúmen. Essas espécies podem ser diferenciadas pela morfologia do talo (monocêntrico, policêntrico e filamentoso/bulboso) e pelo número de flagelos por zoósporo (uniflagelados ou poliflagelados), que podem ser visualizados por meio de microscópio ótico (Ho; Barr, 1995; Ljungdahl, 2008).

A principal espécie encontrada em bovinos é Neocallimastix variabilis, de ciclo monocêntrico, com zoósporos poliflagelados e filamentos com rizomicélio. Os zoósporos possuem 19 flagelos direcionados posteriormente. Esses esporos apresentam quimiotaxia positiva para fragmentos de plantas (Ho et al., 1993).

O Neocallimastix frontalis, um fungo anaeróbio estrito, encontrado no interior do rúmen de ovinos, apresenta ciclo de vida alternado, com uma fase móvel e flagelada; e outra, vegetativa. Os zoósporos apresentam de sete a dez flagelos no gênero Neocallimastix e os cinetossomos (centríolos que se modificam para impulsionar o flagelo) permanecem junto aos flagelos (Orpin, 1983).

A espécie Anaeromyces elegans é isolada no trato digestório bovino. Essa espécie é de ciclo policêntrico, com zoósporos uniflagelados e filamentos com rizomicélio. Após a incubação, os esporos formam uma germinação rizoide. Os zoosporângios são formados em esporangióforos, produzidos pelo rizomicélio e podem ser intercalares ou terminais (Ho et al., 1993). Os fungos anaeróbios do rúmen com ciclo policêntrico apresentam uma etapa evolutiva dentro dos Chitrydiomycetos. Esses, diferentemente daqueles com ciclo monocêntrico, podem se multiplicar por meio da fragmentação do rizomicélio, não dependendo da formação de zoósporos para se perpetuarem no ambiente ruminal (Trinci et al., 1994).

Fungos Neocallimastix spp. e Piromyces spp. são mais eficientes que o Caecomyces spp. na degradação de porções mais resistentes dos vegetais. Neocallimastix frontalis é capaz de solubilizar pequenas quantidades de lignina da parede celular das plantas. Entretanto, não há evidências da utilização desse composto como fonte de carbono (Trinci et al., 1994).

O gênero Caecomyces pode romper fisicamente as fibras vegetais quando ocorre a expansão dos bulbos dos rizoides dentro da estrutura vegetal. Essa habilidade mecânica e a grande atividade de suas polissacaridases justificam a melhor capacidade dos fungos para a utilização das fibras vegetais mais resistentes, quando comparados às diferentes espécies bacterianas do rúmen (Trinci et al., 1994).

Estruturas fúngicas podem ser observadas em todas as partes do trato digestório dos ruminantes, desde as secreções salivares até as porções finais do intestino grosso, o que sugere estágios de resistência no ciclo de vida desses microrganismos (Davies et al., 1993). Amostras de mesmas espécies de fungos apresentam diferenças na sua estrutura quando coletadas de diferentes partes do trato digestório, como intestino grosso e rúmen (Gordon; Phillips, 1992).

Os fungos anaeróbios do rúmen podem assumir importância fundamental na digestão das forragens tropicais, pois produzem enzimas capazes de acelerar a degradação da celulose e hemicelulose lignificadas (Cerdà, 2003). Seus rizóides podem penetrar as fibras lignificadas, desestruturar a parede celular e aumentar a área de superfície da partícula de alimento, o que 
facilita a ação de outros microrganismos (Paul et al., 2004). Bauchop (1979) relatou que, para degradar a parede celular, os fungos podem utilizar três vias: podem invadir o xilema das bainhas das folhas, penetrar pelo anel de esclerênquima das hastes e/ou quebrar a barreira cuticular das folhas.

Nos animais alimentados com dieta rica em fibras, os fungos anaeróbios estritos do rúmen podem representar até oito por cento da biomassa microbiana e estão envolvidos na degradação de celulose e na solubilização da lignina (Akin, 1987). Culturas puras de fungos ruminais são capazes de solubilizar grandes proporções da parede celular vegetal, incluindo os fragmentos mais lignificados. Culturas mistas desses fungos podem degradar até $60 \%$ do material vegetal (Trinci et al., 1994).

A densidade de fungos no rúmen é significativamente influenciada pela frequência de alimentação dos animais. A maior população foi encontrada em animais alimentados seis vezes por dia, sendo observados $15,1 \times 10^{4}$ fungos por grama de conteúdo ruminal. Animais submetidos a uma única oferta de alimento e aqueles alimentados 24 vezes ao dia apresentaram 6,2 a 6,4 x $10^{4}$ fungos, por grama de conteúdo. Fatores reguladores de estímulo ou inibição do equilíbrio da população desses fungos no rúmen podem estar associados ao crescimento de algumas bactérias do rúmen (Obispo; Dehority, 2002).

As celulases microbianas são mundialmente estudadas por vários pesquisadores, com o objetivo de aumentar a liberação de glicose dos substratos, maximizando a fermentação e a produção de etanol. As enzimas provenientes de fungos do rúmen podem degradar a maior parte dos componentes estruturais da parede celular vegetal, tanto em sistemas in vivo como in vitro. Avaliou-se a capacidade de degradação de enzimas extracelulares de Piromyces sp. e Neocallimastix patriciarum em diferentes tipos de substratos contendo lignina e celulose. As enzimas desses fungos converteram até dois por cento $(\mathrm{p} / \mathrm{v})$ de celulose cristalizada para glicose, indicando a atividade de endoglucanases, exoglucanases e $\beta$-glicosidases. Essas enzimas fúngicas foram estáveis até a temperatura de $40^{\circ} \mathrm{C}$, mesmo quando armazenadas durante uma semana (Rembrandt et al., 1997).

\subsubsection{Metabolismo fúngico}

Fungos anaeróbios da microbiota autóctone do rúmen são muito sensíveis ao oxigênio e a temperatura e, geralmente não sobrevivem em condições diferentes das encontradas no trato gastrointestinal de animais (Ljungdahl, 2008).

Sabe-se que esses fungos conseguem se desenvolver utilizando amônia como fonte de nitrogênio, entretanto, há dados na literatura que sugerem benefício a essa população quando se suplementa aminoácidos. Lisina, metionina e histidina são aminoácidos (aa's) identificados como estimulatórios aos fungos ruminais (Onoda et al., 1996).

O fornecimento de uma mistura completa de aa's para fungos ruminais, $N$. frontalis e $P$. communis, estimulou a utilização da xilana, o crescimento microbiano e a produção microbiana (Guliye; Wallace, 2007).

Pesquisas têm sugerido que em herbívoros, esses organismos são os colonizadores iniciais da lignocelulose e são essenciais na digestão da fibra. Fungos anaeróbios do rúmen fermentam os açúcares, obtendo-se formato, acetato, etanol, lactato, $\mathrm{CO}_{2}$ e $\mathrm{H}_{2}$ como principais produtos. Referente à habilidade em produzir enzimas hidrolíticas, destacam-se: celulases, $\beta$-glucosidases, xilanases, $\beta$-glucanases, mananases, cinamoil esterases / esterases feruloyl e $p$-coumaroyl, acetil xilano esterase, (4-0-metil)-D-glucuronidase / $\alpha$-glucuronidase (Borneman et al., 1989; Ljungdahl, 2008).

Os sistemas de enzimas celulolíticas de bactérias e fungos aeróbios diferem daqueles encontrados em bactérias e fungos anaeróbios estritos. Microrganismos celulolíticos aeróbicos, como o fungo Trichoderma reesei e bactérias Cellulomonas fimi, produzem e secretam 
separadamente enzimas que atuam de forma sinérgica para degradar a celulose cristalina. Em contraste, muitas bactérias anaeróbias produzem complexos multienzimáticos extracelulares chamados celulosomas, que efetivamente hidrolisam celulose e hemicelulose (Bayer et al., 2004).

Celulosomas são organelas exocelulares com cerca de 3 milhões Da, que também existem como policelulosomas de até 100 milhões $\mathrm{Da}$. Os celulossoma de fungos anaeróbios se localizam na superfície da extremidade do micélio. Assim, os celulossomas mediam o ataque das células fúngicas ao tecido da planta. Esse arranjo permite que as enzimas do celulossoma atuem sobre a camada de hemicelulose/lignina da planta, facilitando a penetração das hifas (Akin, 1989; Ljungdahl, 2008).

Recentes relatos também apontam a participação de fungos ruminais no processo de biohidrogenação no rúmen. De acordo com Nam e Garnsworthy (2007), diferenças são observadas na taxa de biohidrogenação entre isolados fúngicos, que podem ser causadas por variações no ciclo de vida ou na taxa de crescimento fúngico.

\section{SUPLEMENTAÇÃO MICROBIANA EM DIETAS DE RUMINANTES}

Culturas microbianas vivas dos fungos exógenos Aspergillus oryzae e Saccharomyces cerevisiae e os seus respectivos extratos têm sido utilizados como suplementos alimentares na dieta dos animais. Aditivos microbianos podem melhorar a produtividade de ruminantes em aproximadamente sete a oito por cento (Martin; Nisbet, 1992; Wallace, 1994).

A ação benéfica desses microrganismos no ambiente ruminal associa-se ao aumento da ingestão de matéria seca, sendo proporcionada por elevação significativa na taxa de degradação da fibra, especialmente em dietas ricas em concentrado. Há aumento expressivo no número total de bactérias anaeróbias e, entre elas, as celulolíticas e as utilizadoras de lactato. Tem sido observada maior estabilidade no ambiente ruminal, reduzindo-se variações de $\mathrm{pH}$, de amônia e de ácidos graxos voláteis ao longo do dia (Wallace, 1994).

Quando vacas leiteiras são submetidas a situações de estresse por calor, a administração da cultura de Aspergillus oryzae promove aumento na produção de leite e redução da temperatura retal durante o verão (Huber et al., 1994). Suplementação com Saccharomyces cerevisiae em dieta de vacas lactantes sob estresse por calor ocasiona incremento na produção de leite, teores mais elevados de proteína verdadeira, sólidos não gordurosos e lactose do leite (Bruno et al., 2009).

De acordo com Caton et al. (1993), a suplementação com extrato de Aspergillus oryzae promoveu aumento no consumo de forragens. No estudo, foi observado aumento da digestibilidade in vitro da matéria seca, contudo, o fungo não alterou as proporções e concentração de AGV's, pH ruminal e amônia total.

Abdelrahman e Hunaiti (2008) relatam que a suplementação com a levedura Saccharomyces cerevisiae e com o aminoácido metionina em dietas para cordeiros em crescimento melhora a biodisponibilidade de cobre, zinco e cobalto, reduz a conversão alimentar e, promove aumento no ganho de peso total e ganho de peso médio diário. Outra pesquisa, avaliando a suplementação dessa levedura para ovelhas alimentadas com cana de açúcar, destaca aumento na concentração de AGV's, e nenhum efeito sobre a proporção molar de AGV's, população de protozoários e digestibilidade (Arcos-García et al., 2000).

$O$ efeito de um produto contendo Saccharomyces cerevisiae foi avaliado em função da colonização microbiana do rúmen de cordeiros recém-nascidos. Foi constatado que o aditivo tende a estimular o crescimento de bactérias celulolíticas. A densidade desses microrganismos foi superior em cordeiros recebendo suplementação quando comparada ao grupo controle. $O$ estabelecimento de protozoários também ocorreu mais cedo no rúmen de cordeiros recebendo probiótico diariamente. Durante a primeira semana de nascimento os animais passaram a ingerir alimentos sólidos e os parâmetros físico-químicos e fermentativos foram alterados no rúmen de 
cordeiros que tinham recebido levedura, sugerindo processos de fermentação mais eficientes. Os efeitos foram em parte devido à capacidade de redução do potencial redox no rúmen de cordeiros tratados. Estes resultados representam bons argumentos para sugerir que a suplementação com aditivos microbianos pode ser capaz de acelerar a funcionalidade ruminal, ou melhorar a estabilidade microbiana do rúmen em animais jovens (Chaucheyras-Durand; Fonty, 2002).

Em contrapartida, para ovelhas, cepas de Saccharomyces cerevisiae não influenciaram na concentração de AGV's, população de protozoários, N-amoniacal, aminoácidos duodenais e digestibilidade total de matéria seca (MS), matéria orgânica (MO), fibra em detergente neutro (FDN) e fibra em detergente ácido (FDA) (Angeles et al., 1998). Segundo Cabrera et al. (2000), o fornecimento dessa levedura não melhorou o desempenho de novilhos criados em pastagens tropicais e nem a disponibilidade da fibra.

Os efeitos positivos mais consistentes da atividade de leveduras secas foram reportados sobre a atividade microbiana ruminal em ruminantes jovens, a estabilização do pH ruminal e prevenção de acidose, bem como a estimulação de crescimento e atividade de degradação da fibra por bactérias (Chaucheyras-Durand et al., 2008).

Quanto a redução de microrganismos patogênicos, a suplementação com Saccharomyces cerevisiae ou Lactobacillus acidophilus promoveu a morte de cepas de Escherichia coli produtoras de toxina Shiga durante a incubação prolongada no conteúdo ruminal (Chaucheyras-Durand et al., 2010). O compartimento do rúmen atua como um reservatório importante de enterobactérias e pode ser um alvo relevante para diminuir o número de células viáveis de $E$. coli e consequentemente, contaminação de alimentos (Chaucheyras-Durand et al., 2010).

Em outro estudo, a administração de um produto contendo essa mesma combinação microbiana para bezerros mestiços não interferiu no número de bactérias láticas, leveduras e coliformes presentes no rúmen e no intestino. Foi constatado também que a atividade das enzimas carboximetilcelulase, xilanase, $\beta$-glicosidase, $\alpha$-glicosidase, $\alpha$-amilase, protease, urease e $\mathrm{pH}$ ruminal apresentam-se inalterados pós-administração desses microrganismos (Agarwal et al., 2002).

Poucos estudos na literatura avaliaram o efeito da administração de culturas com fungos da microbiota autóctone do rúmen na dieta dos bovinos. A adição de culturas viáveis de $P$. communis aumentou a produção de gás, a digestão da celulose, o número total de bactérias, de bactérias celulolíticas e de fungos anaeróbios. Observou-se o aumento da atividade das enzimas carboximetil celulase e xilanase, quando comparado com sistemas fermentativos controles não suplementados. A adição do fungo, demonstrou ser favorável ao crescimento de culturas mistas de microrganismos ruminais (Lee et al., 2000).

A adição direta de $P$. communis no rúmen de ovinos melhorou a digestibilidade de nutrientes e a retenção de nitrogênio, aumentou o número de bactérias e fungos e, consequentemente, incrementou a produção de AGV's. Esse fungo, diferentemente do Aspergillus oryzae e da levedura Saccharomyces cerevisiae, é anaeróbio e continua sua multiplicação no rúmen após a inoculação (Lee et al., 2000).

Diferenças de resultados encontrados com a suplementação microbiana são atribuídas à utilização de cepas distintas, diferenças nos aditivos comerciais e composição da dieta (Wallace, 1995; Angeles et al., 1998; Arcos-García et al., 2000). Chaucheyras-Durand et al. (2008) referenciam que efeitos de leveduras secas podem variar dependendo de fatores bióticos como a viabilidade da cepa, mas também de fatores abióticos, como a natureza da dieta ou manejo animal.

\subsection{Mecanismo de ação dos aditivos microbianos}

Vários estudos têm respaldado efeitos de anaeróbios facultativos no rúmen na estabilização do $\mathrm{pH}$. De fato, tem sido demonstrado in vitro que uma cepa de $S$. cerevisiae foi 
capaz de reduzir a prevalência de Streptococcus bovis, quando concorrem para a utilização de açúcares, o que consequentemente limitou a quantidade de lactato produzida por esta espécie bacteriana. Além disso, a estimulação do metabolismo de lactato e, crescimento de bactérias, como Megasphaera elsdenii ou Selenomonas ruminantium, tem sido observado in vitro na presença de leveduras (Chaucheyras et al., 1996).

Suplementação com a levedura $S$. cerevisiae tende a aumentar a população de protozoários ruminais, que são conhecidos por engolfarem rapidamente grânulos de amido. Este fator contribui para uma estabilização mais eficiente do pH ruminal (Brossard et al., 2006).

Quando o pH ruminal é baixo, a diversidade microbiana reduz, populações de protozoários sofrem declínio e as bacterianas são alteradas (Martin et al., 2006). Se pH ruminal continua a cair, os Lactobacillus spp. podem substituir as bactérias S. bovis, iniciando um acúmulo excessivo de lactato, levando à acidose metabólica (Russell; Hino, 1985). Dessa forma, evidencia-se a relevância da utilização de aditivos microbianos na alimentação de ruminantes, principalmente daqueles confinados por um período mais longo, arraçoados com alto teor de concentrado.

Fungos anaeróbios do rúmen também podem auxiliar na degradação da fibra vegetal. A germinação de zoósporos de fungos anaeróbios Neocallimastix frontalis foi estimulada por cepas de S. cerevisiae (Chaucheyras et al., 1995). In vitro, cepas de S. cerevisiae incrementaram o crescimento de Fibrobacter succinogenes $\mathrm{S} 85$ e reduziu a fase Lag de crescimento de Ruminococcus albus 7, Ruminococcus flavefaciens FD1 e Butyrivibrio fibrisolvens D1 (Girard; Dawson, 1995). O efeito benéfico sobre a digestão da fibra pode ser em parte responsável pelo aumento no consumo de MS, frequentemente observado com a administração microbiana na dieta (Jouany, 2006).

Um dos principais fatores implicados no efeito benéfico da degradação de fibra por bactérias é a capacidade das células leveduriformes consumirem o oxigênio que chega no ambiente ruminal, otimizando as condições de anaerobiose para as celulolíticas (ChaucheyrasDurand et al., 2008). Estudos relataram que o potencial redox de líquido ruminal foi menor na presença de leveduras em dietas de cordeiros (Chaucheyras-Durand; Fonty, 2002).

Dados recentes sugerem alterações no metabolismo de nitrogênio por microrganismos ruminais na presença de leveduras. Achados in vitro indicaram que uma cepa de S. cerevisiae pôde reduzir o crescimento e a atividade de bactérias proteolíticas no rúmen, limitando a ação bacteriana sobre proteínas e peptídeos (Chaucheyras-Durand et al., 2005). Outros trabalhos evidenciam a redução na concentração de amônia com administração dessa levedura (Chaucheyras-Durand; Fonty, 2002).

Lynch e Martin (2002) reportam a diminuição de $20 \%$ na produção de metano após um período de 48 horas de incubação de microrganismos ruminais e leveduras vivas na presença de alfafa.

Dutta et al. (2009) em uma revisão bibliográfica reporta como efeitos da suplementação de leveduras na fermentação ruminal a estabilização da fermentação e do pH ruminal, a alteração na produção de AGV's, a redução na concentração de amônia, o aumento na concentração de bactérias anaeróbias, bactérias celulolíticas, leveduras e síntese de proteína microbiana, a redução na produção de metano, o decréscimo na concentração de ácido lático. Descrevem também que ocorre alteração no padrão digestivo com redução na concentração de açúcares solúveis, aumento na concentração de etanol, aumento do propionato e redução do acetato.

\section{CONSIDERAÇÕES FINAIS}

O ambiente ruminal possui complexo ecossistema microbiano, responsável pela fermentação do alimento e contribui para suprir as exigências nutricionais dos animais. Contudo, justamente por ser diversificada e influenciada por diversos fatores, torna-se difícil modular a microbiota do rúmen em função das respostas que se deseja obter no sistema de produção. Dessa 
forma, é de grande relevância conhecer as principais espécies microbianas que habitam esse ambiente, bem como seus mecanismos de ação e vias metabólicas. Baseado nesses conhecimentos, será possível alcançar ganhos na produção, otimizando a degradação dos alimentos. Adicionalmente, a suplementação de probióticos ou aditivos microbianos poderia se tornar mais eficiente, uma vez que o mecanismo de ação seria direcionado.

Diferentes entraves ainda ocorrem no campo para o emprego de aditivos na produção animal. Resultados diversos são encontrados, muitas vezes justificados pela condição do animal, cepa utilizada e viabilidade do produto. Futuros estudos tornam-se necessários para elucidar a melhor forma de administração, aplicabilidade, para viabilizar a elaboração de novos aditivos, para um ganho mais efetivo nos rebanhos, especialmente àqueles condicionados ao clima tropical, com escassez de chuvas e alimentos de baixo valor nutricional.

\section{AGRADECIMENTOS}

Á Universidade Federal de Minas Gerais. Ao CNPq e FAPEMIG. E ao Instituto Federal Goiano.

\section{REFERÊNCIAS}

ABDELRAHMAN, M. M.; HUNAITI, D. A. The effect of dietary yeast and protected methionine on performance and trace minerals status of growing Awassi lambs. Livestock Science, v. 115, p. 235241, 2008. https://doi.org/10.1016/j.livsci.2007.07.015

ABECIA, L.; MARTíN-GARCÍA, A. I.; MARTíNEZ, G.; NEWBOLD, C. J.; YÁÑEZ-RUIZ, D. R. Nutritional intervention in early life to manipulate rumen microbial colonization and methane output by kid goats postweaning. Journal of Animal Science, v. 91, p. 4832-4840, 2013. https://doi.org/10.2527/jas.2012-6142

ABRÃO, F. O. Análises microbiológicas e físico-químicas do fluido ruminal de bovinos de corte criados em pastagens tropicais: período seco. (Monografia) Montes Claros, MG: ICA/UFMG, 2009. $43 \mathrm{f}$.

ABRÃO, F. O.; FREITAS, C. E. S.; DUARTE, E. R.; GERASEEV, L. C.; BARRETO, S. M. P.; MEdEIROS, A. O.; ROSA, C. A. Leveduras no rúmen de caprinos e bovinos de corte criados em pastagem tropicais. Arquivo Brasileiro de Medicina Veterinária e Zootecnia, v. 63, n. 2, p. 526-529, 2011. https://doi.org/10.1590/S0102-09352011000200039

ABRÃO. F. O.; DUARTE, E. R.; FREITAS, C. E. S.; VIEIRA, E. A.; GERASEEV, L. C.; SILVA-HUGHES, A. F.; ROSA, C. A.; RODRIGUES, N. M. Characterization of Fungi from Ruminal Fluid of Beef Cattle with Different Ages and Raised in Tropical Lignified Pastures. Current Microbiology, v. 69, n. 2, p. 64959, 2014.

AGARWAL, N.; KAMRA, D. N.; CHAUDHARY, L. C.; AGARWAL, I.; SAHOO, A.; PATHAK, N. N. Microbial status and rumen enzyme profile of crossbred calves fed on different microbial feed additives. Letters in Applied Microbiology, v. 34, p. 329-336, 2002. https://doi.org/10.1046/j.1472-765X.2002.01092.x

AKIN, D. E. Association of rumen fungi with various forage grasses. Animal Feed Science and Technology, v. 16, n. 4, p. 273-285, 1987. 
AKIN, D. E.; LYON, C. E.; WINDHAM, W. R.; RIGSBY, L. L. Physical degradation of lignified stem tissue by ruminal fungi. Applied Environmental Microbiology, v. 55, p. 611-616, 1989. https://doi.org/10.1016/0377-8401(87)90016-2

ALMEIDA, P. N. M. Análise da população microbiana e caracterização de fungos com atividade celulolítica em fluido ruminal de bovinos leiteiros alimentados com diferentes forragens. Dissertação (Mestrado em Ciências Agrárias), Universidade Federal de Minas Gerais, Montes Claros. 88 f., 2009.

ALMEIDA, P. N. M.; FREITAS, C. E. S.; ABRÃO, F. O.; RIBEIRO, I. C. O.; VIEIRA, E. A.; GERSEEV, L. C.; DUARTE, E. R. Atividade celulolítica de fungos aerobios isolados do rúmen de bovinos leiteiros alimentados com forragens tropicais. Revista Caatinga, v. 27, n. 4, p. 202 - 207, 2014.

ANGELES, S. C.; MENDOZA, G. D.; COBOS, M. A.; CROSBY, M. M.; CASTREJÓN, F. A. Comparison of two commercial yeast cultures (Saccharomyces cerevisiae) on ruminal fermentation and digestion in sheep fed on corn-stover diet. Small Ruminant Research, v. 31, p. 45-50, 1998. https://doi.org/10.1016/S0921-4488(98)00115-1

ARCOS-GARCíA, J. L.; CASTREjón, F. A.; MENDOZA, G. D.; PÉREZ-GAVILÁN, E. P. Effect of two commercial yeast cultures with Saccharomyces cerevisiae on ruminal fermentation and digestion in sheep fed sugar cane tops. Livestock Production Science, v. 63, p. 153-157, 2000. https://doi.org/10.1016/S0301-6226(99)00116-5

ARCURI, P. B.; LOPES, F. C. F.; CARNEIRO, J. C. Microbiologia do rúmen. In: Nutrição de ruminantes, 2011. p. 115 - 160. 2ed. p. 616: il.

ABPA - Associação Brasileira de Proteína Animal. Cenário de carnes 2014/2015. 2015.

BAUCHOP, P. The rumen anaerobic fungi: colonizers of plant fibre. Annals of Veterinary Research, v. 10, n. 2, p. 246-248, 1979.

BAYER, E. A; BELAICH, J. P.; SHOHAM, Y.; LAMED, R. The Cellulosomes: multienzyme machines for degradation of plant cell wall polysaccharides. Annual Reviews Microbiology, v. 58, p. 521-554, 2004. https://doi.org/10.1146/annurev.micro.57.030502.091022

BELANCHE, A.; LA FUENTE, G.; NEWBOLD, C. J. Study of methanogen communities associated with different rumen protozoal populations. FEMS Microbiol Ecology, p. 1-15, 2014. https://doi.org/10.1111/1574-6941.12423

BÉRA-MAILleT, C.; DEVILlARD, E.; CEZETTE, M.; JOUANY, J.; FORANO, E. Xylanases and carboxymethylcellulases of the rumen protozoa Polyplastron multivesiculatum, Eudiplodinium maggii and Entodinium sp. FEMS Microbiology Letters, v. 244, p. 149-156, 2006. https://doi.org/10.1016/i.femsle.2005.01.035

BERARD, N. C.; HOLLEY, R. A.; MCALLISTER, T. A.; OMINSKI, K. H.; WITTENBERG, K. M.; BOUCHARD, K. S.; BOUCHARD, J. J.; KRAUSE, D. O. Potential To Reduce Escherichia coli Shedding in Cattle Feces by Using Sainfoin (Onobrychis viciifolia) Forage, Tested In Vitro and In Vivo. Applied and Environmental Microbiology, p. 1074-1079, 2009. https://doi.org/10.1128/AEM.00983-08 
BORNEMAN, W. S.; AKIN, D. E.; LJUNGDAHL, L. G. Fermentation products and plant cell walldegrading enzymes produced by monocentric and polycentric anaerobic ruminal fungi. Applied Environmental Microbiology, v. 55, p. 1066-1073, 1989.

BROSSARD, L.; CHAUCHEYRAS-DURAND, F.; THE LATE MICHALET-DOREAU, B.; MARTIN, C. Dose effect of live yeasts on rumen microbial communities and fermentations during butyric latent acidosis in sheep: newtype of interaction. Animal Science, v. 82, p. 1- 8, 2006. https://doi.org/10.1017/ASC200693

BRUNO, R. G. S.; RUTIGLIANO, H. M.; CERRI, R. L.; ROBINSON, P. H.; SANTOS, J. E. P. Effect of feeding Saccharomyces Cerevisiae on performance of dairy cows during summer heat stress. Animal Feed Science and Technology, v. 150, p. 175-186, 2009. https://doi.org/10.1016/i.anifeedsci.2008.09.001

CABRERA, E. J. I.; MENDOZA, M. G. D.; ARANDA, I. E.; GARCIA-BOJALIL, C.; BÁRCENA, G. R.; RAMOS, J. J. A. Saccharomyces cerevisiae and nitrogenous supplementation in growing steers grazing tropical pastures. Animal Feed Science and Technology, v. 83, p. 49-55, 2000. https://doi.org/10.1016/S0377-8401(99)00109-1

CALLAWAY, T. R.; ANDERSON, R. C.; EDRINGTON, T. S.; GENOVESE, K. J.; BISCHOFF, K. M.; POOLE, T. L.; JUNG, Y. S.; HARVEY, R. B.; NISBET, D. J. What are we doing about Escherichia coli O157:H7 in cattle? Journal of Animal Science, v. 82, p. E93-E99, 2004.

CALLAWAY, T. R.; CARR, M. A.; EDRINGTON, T. S. Diet, Escherichia coli 0157:H7, and cattle: a review after 10 years. Current Issues Molecular Biology, v. 11, n. 2, p.67-79, 2009.

CATON, J. S.; ERICKSON, D. O.; CAREY, D. A.; ULMER, D. L. Influence of Aspergillus oryzae fermentation extract on forage intake, site of digestion, in situ degradability, and duodenal amino acid flow in steers grazing cool-season pasture. Journal of Animal Science, v. 71, p. 779-787, 1993. https://doi.org/10.2527/1993.713779x

CERDÀ, A. R. Fermentación Ruminal, Degradación Protéica y Sincronización Energía-Proteína en Terneras en Cebo Intenso. Tese (Doutorado) em Produção Animal - Universitat Autónoma de Barcelona, Espanha, 196 f., 2003.

CHAUCHEYRAS-DURAND, F.; FAQIR, F.; AMEILBONNE, A.; ROZAND, C.; MARTIN, C. Fates of acidresistant and non-acid-resistant shiga toxin-producing Escherichia coli Strains in ruminant digestive contents in the absence and presence of probiotics. Applied and environmental microbiology, $\mathrm{v}$. 76, n. 3, p. 640-647, 2010. https://doi.org/10.1128/AEM.02054-09

CHAUCHEYRAS-DURAND, F.; FONTY, G. Influence of a probiotic yeast (Saccharomyces cerevisiae CNCM I-1077) on microbial colonization and fermentations in the rumen of newborn lambs. Microbial Ecology in Health and Disease, p. 30- 36, 2002.

CHAUCHEYRAS, F.; FONTY, G.; BERTIN, G.; GOUET, P. Effects of live Saccharomyces cerevisiae cells on zoospore germination, growth, and cellulolytic activity of the rumen anaerobic fungus, Neocallimastix frontalis MCH3. Current Microbiology, v. 31, p. 201-205, 1995. https://doi.org/10.1007/BF00298373 
CHAUCHEYRAS, F.; FONTY, G.; BERTIN, G.; SALMON, J. M.; GOUET, P. Effects of a strain of Saccharomyces cerevisiae (Levucell SC), a microbial additive for ruminants, on lactate metabolism in vitro. Canadian Journal Microbiology, v. 42, p. 927-933, 1996. https://doi.org/10.1139/m96-119

CHAUCHEYRAS-DURAND, F.; MADIC, J.; DOUNDIN, F.; MARTIN, C. Biotic and Abiotic Factors Influencing In Vitro Growth of Escherichia coli 0157:H7 in Ruminant Digestive Contents. Applied and Environmental Microbiology, n. 6, v. 72, p. 4136-4142, 2006. https://doi.org/10.1128/AEM.02600-05

CHAUCHEYRAS-DURAND, F.; MASSEGLIA, S.; FONTY, G. Effect of the microbial feed additive Saccharomyces cerevisiae CNCM I-1077 on protein and peptide degrading activities of rumen bacteria grown in vitro. Current Microbiology, v. 50, p. 96-101, 2005. https://doi.org/10.1007/s00284-004-4433-1

CHAUCHEYRAS-DURAND, F.; WALKER, N. D.; BACH, A. Effects of active dry yeasts on the rumen microbial ecosystem: Past, present and future. Animal Feed Science and Technology, v. 145, p. 526, 2008. https://doi.org/10.1016/i.anifeedsci.2007.04.019

DUNCAN, S. H.; DOHERTY, C. J.; GOVAN, J. R. Characteristics of sheep-rumen isolates of Pseudomonas aeruginosa inhibitory to the growth of Escherichia coli O157. FEMS Microbiology Letters, v. 180, p. 305-310, 1999. https://doi.org/10.1111/j.1574-6968.1999.tb08810.x

DAVIES, D. R.; THEODOROU, M. K.; LAWRENCE, M. I. G.; TRINCI A. P. Distribution of anaerobic fungi in the digestive tract of cattle and their survival in faeces. Journal of General Microbiology, v. 139, p. 1395-1400, 1993. https://doi.org/10.1099/00221287-139-6-1395

DEHORITY, B. A. Microbial Interactions in the Rumen. Revista de la Facultad de Agronomía, v. 15, n. 1, p. 69-86, 1998.

DUTTA, T. K.; KUNDU, S. S.; KUMAR, M. Potential of direct-fed-microbials on lactation performance in ruminants - a critical review. Livestock Research for Rural Development, v. 21, n. 10, 2009.

FAEMG, Federação da Agricultura e Pecuária do Estado de Minas Gerais, 2013. Disponível em: <http://www.faemg.org.br/Content.aspx?Code=9\&ParentCode=2\&ParentPath= None\&ContentVersion=C>. Acesso em: 20 out. 2014.

FLINT, H. J. Molecular genetics of obligate anaerobes from the rumen. FEMS Microbiology Letters, (The Netherlands), v. 121, p. 259-267, 1994.

FRANZOLIN, R.; DEHORITY, B. A. Efeitos do pH ruminal e ingestão alimentar na defaunação em ovinos sob rações concentradas. Revista da Sociedade Brasileira de Zootecnia, v. 25, n. 6, p. 12071215, 1996.

FREITAS, C. E. S; ALMEIDA, P. N.; DUARTE, E. R.; ABRÃO, F. O.; CARELI, R.; GERASEEV, L. C. Aerobes and anaerobe facultative Gram-negative bacteria rod-shaped in the ruminal fluid of dairy cattle fed with different diets containing tropical forages. Archivos de Medicina Veterinaria, v. 46, p. 457462, 2014. https://doi.org/10.4067/S0301-732X2014000300017 
GATTASS, C. B. A.; MORAIS, M. G.; ABREU, U. G. P.; FRANCO, G. L.; STEIN, J.; LEMPP, B. Efeito da suplementação com cultura de levedura na fermentação ruminal de bovinos de corte. Revista Brasileira de Zootecnia, v. 37, n. 4, p. 711-716, 2008. https://doi.org/10.1590/S151635982008000400018

GERÔNIMO, D. M. Caracterização molecular de três genes da via da lignificação em plantas forrageiras tropicais. Dissertação. Pirassununga: University of São Paulo, Faculdade de Medicina Veterinária e Zootecnia; 2011 [Accessed 2015-11-22]. Available from: http://www.teses.usp.br/teses/disponiveis/10/10135/tde-27092012-182653/.

GILBERT, R. A.; TOMKINS, N.; PADMANABHA, J.; GOUGH, J. M.; KRAUSE, D. O.; McSWEENEY, C. S. Effect of finishing diets on Escherichia coli populations and prevalence of enterohaemorrhagic $E$. coli virulence genes in cattle faeces. Journal of Applied Microbiology, v. 99, p. 885-894, 2005. https://doi.org/10.1111/j.1365-2672.2005.02670.x

GIRARD, I. D.; DAWSON, K. A. Effect of a yeast culture on growth characteristics of representative ruminal bacteria. Journal of Animal Science, v. 73, p. 264, 1995.

GORDON, G. L. R.; PHILLIPS, M. W. Extracellular Pectin Lyase Produced by Neocallimastix sp. LM1, a Rumen Anaerobic Fungus. Letters in Applied Microbiology, v. 15, n. 3, p. 113-115, 1992. https://doi.org/10.1111/j.1472-765X.1992.tb00740.x

GULIYE, A. Y.; WALLACE, R. J. Effects of aromatic amino acids, phenylacetate and phenylpropionate on fermentation of xylan by the rumen anaerobic fungi, Neocallimastix frontalis and Piromyces communis. Journal of Applied Microbiology, v. 103, p. 924-929, 2007. https://doi.org/10.1111/i.1365-2672.2007.03327.x

HO, Y. W.; BARR, D. J. S. Classification of anaerobic fungi from herbivores with emphasis on rumen fungi from Malaysia. Mycologia, v. 87, n. 5, p. 655-677, 1995. https://doi.org/10.2307/3760810

HO, Y. W.; BAUCHOP, T.; ABDULLAH, N.; JALALUDIN, S.; KUDO, H., Neocallimastix variabilis, a new species of anaerobic fungus from the rumen of cattle. Mycotaxon, v. 46, p. 241-258, 1993.

HUBER, J. T.; HIGGINBOTHAM, G.; GOMEZ-ALARCON, R. A.; TAYLOR, R. B.; CHEN, K. H.; CHAN, S. C.; WU, Z. Heat stress interactions with protein, supplemental fat, and fungal cultures. Journal Dairy Science, v. 77, p. 2080-2090, 1994. https://doi.org/10.3168/jds.S0022-0302(94)77151-4

JOUANY, J. P. Optimizing rumen functions in the close-up transition period and early lactation to drive dry matter intake and energy balance in cows. Animal Reproduction Science, v. 96, p. 250264, 2006. https://doi.org/10.1016/i.anireprosci.2006.08.005

KAMRA, D. N. Rumen Microbial Ecosystem. Current Science, v. 89, n. 1, p. 125- 35, 2005.

LEE S. S.; HA, J. K.; CHENG, K. J. Influence of an anaerobic fungal culture administration on in vivo ruminal fermentation and nutrient digestion. Animal Feed Science and Technology, v. 88, p. 201217, 2000. https://doi.org/10.1016/S0377-8401(00)00216-9

LEJEUNE, J. T.; WETZEL, A. N. Preharvest control of Escherichia coli 0157 in cattle. Journal of Animal Science, v. 85, p. E73-E80, 2007. https://doi.org/10.2527/jas.2006-612 
LI, J.; HEATH, I. B.; PACKER, L. The phylogenetic relationships of the anaerobic chytridiomycetous gut fungi (Neocallimasticaceae) and the Chytridiomycota. II. Cladistic analysis of structural data and description of Neocallimasticales ord. nov. Canadian Journal of Botany, v. 71, p. 393-407, 1993. https://doi.org/10.1139/b93-044

LJUNGDAHL, L. G. The Cellulase/Hemicellulase System of the Anaerobic Fungus Orpinomyces PC-2 and Aspects of Its Applied Use. Annual N.Y. Academic Science, v. 1125, p. 308-321, 2008. https://doi.org/10.1196/annals.1419.030

LYNCH, H. A.; MARTIN, S. A. Effects of Saccharomyces cerevisiae culture and Saccharomyces cerevisiae live cells on in vitro mixed ruminal microorganism fermentation. Journal Dairy Science, v. 85, p. 2603-2608, 2002. https://doi.org/10.3168/jds.S0022-0302(02)74345-2

MADINGAN, M. T.; MARTINKO, J. M.; DUNLAP, P. V.; CLARK, D. P. Microbiologia de Brock. 12a Ed. Porto Alegre: Artmed, 2010. 1160 p.

MAGALHÃES, D. Q.; ABRÃO, F. O.; FREITAS, C. E. S.; SILVA, K. L.; ALMEIDA, P. N. M.; DUARTE, E. R. Micobiota aeróbia do trato gastrintestinal de vacas e bezerros de corte criados em pastagens tropicais: período seco. Anais...In: XX Zootec, Palmas- Tocantins. 2010.

MARTILENE, I.; D'AGOSTO, M. Predação e canibalismo entre protozoários ciliados (Ciliophora: Entodiniomorphida: Ophryoscolecidade) no rúmen de ovinos (Ovis aries). Revista Brasileira de Zoologia, v. 25, n. 3, p. 451-455, 2008. https://doi.org/10.1590/S0101-81752008000300010

MARTILLOTTI, F. Microbial and Chemical Characterization of Rumen Contents of Grazing Dairy Cows. In: PRINS, R. A.; STEWART, C. S. (Ed.). Micro-organisms in Ruminant Nutrition. Dalfsen: Nottingham University Press, 1994.

MARTIN, A. S.; NISBET, D. J. Effect of direct-feed microbial on rumen microbial fermentation. Journal of Dairy Science, v. 75, n. 6, p. 1736-1744, 1992. https://doi.org/10.3168/jds.S0022$\underline{0302(92) 77932-6}$

MARTIN, C.; BROSSARD, L.; DOREAU, M. Mécanismes d'apparition de l'acidose ruminale latente et conséquences physiopathologiques et zootechniques. INRA Productions Animales, v. 19, p. 93108, 2006.

MORVAN, B.; DORÉ, J.; RIEU-LESME, F.; FOUCAT, L.; FONTY, G.; GOUET, P. Establishment of hydrogen-utilizing bacteria in the rumen of the newborn lamb. FEMS Microbiology Letters, v. 117, p. 249-256, 1994. https://doi.org/10.1111/j.1574-6968.1994.tb06775.x

NAGARAJA, T. G.; NEWBOLD, C. J.; VAN NEVEL, C. J. Manipulation of ruminal fermentation. In: The Rumen Microbial Ecosystem. Editado por HOBSON, P. N.; STEWART, C. S. London: Chapman and Hall, p. 523-632. 1997. https://doi.org/10.1007/978-94-009-1453-7 13

NAM, I. S.; GARNSWORTHY, P. C. Biohydrogenation of linoleic acid by rumen fungi compared with rumen bacteria. Journal of Applied Microbiology, v. 103, p. 551-556, 2007. https://doi.org/10.1111/i.1365-2672.2007.03317.x 
NOORAEE, S. E.; ALIMON, A. R.; HO, Y. W.; ABDULLAH, N. Characterization of Kluyveromyces marxianus as a potential feed additive for ruminants. Letters in Applied Microbiology, v. 50, p. 578-584, 2010. https://doi.org/10.1111/j.1472-765X.2010.02836.x

OBISPO, N. E.; DEHORITY, B. A. Factores affecting the concentration and cellulolytic activity of sheep rumen fungi. Livestock Research for Rural Development, v. 14, n. 5, p. 5-10, 2002.

OLIVEIRA, J. S.; ZANINE, A. M.; SANTOS, E. M. Diversidade microbiana no ecossistema ruminal. Revista eletrónica de Veterinaria (REDVET), v. 8, n. 6, 2007.

ONODA, A.; KOBAYASHI, Y.; HOSHINO, S. Effects of amino acids on the growth of an anaerobic rumen fungus Neocallimastix sp N 13. Reproducion and Nutricion Development, v. 36, p. 311-320, 1996. https://doi.org/10.1051/rnd:19960308

ORPIN, C. G. The role of ciliate protozoa and fungi in the rumen digestion of plant cell wall. Animal Feed Science and Technology, v. 10, n. 2, p. 121-143, 1983.

OYELEKE, S. B., OKUSANMI, T. A. Isolation and characterization of cellulose hydrolyzing microorganism from the rumen of ruminants. African Journal of Biotechnology, v. 7, p. 1530-1504, 2008.

OZKOSE, E., THOMAS, B. J., DAVIES, D. R., GRIFFITH, G. W.; THEODOROU, M. K. Cyllamyces aberensis gen.nov. sp.nov., a new anaerobic gut fungus with branched sporangiophores isolated from cattle. Canadian Journal Botanic, v. 79, p. 666-673, 2001. https://doi.org/10.1139/b01-047

PAUL K.; NONOH J. O., MIKULSKI L.; BRUNE A. "Methanoplasmatales", thermoplasmatales-related Archaea in termite guts and other environments, are the seventh order of methanogens. Applied Environmental Microbiology, v. 78, p. 8245-8253, 2012. https://doi.org/10.1128/AEM.02193-12

PAUL, S. S.; KAMRA, D. N.; SASTRY, V. R. B.; SAHU, N. P.; AGARWAL, N. Effect of anaerobic fungi on in vitro feed digestion by mixed rumen microflora of buffalo. Reproduction Nutrition Development, v. 44, n. 4, p. 313-319, 2004. https://doi.org/10.1051/rnd:2004036

PESSOA, M. S. Características físico-químicas e microbiológicas da silagem ácida de pescado. Dissertação (Mestrado) em Agroecologia - Universidade Federal de Minas Gerais, 46 f., 2012.

REMBRANDT, D.; BAHNSING, D. C. P.; CAMP, H. J. M. O.; DRIFT, C. V.; VOGELS, G. Degradation of structural pohysaccharides by the plant cell-wall degrading inzyme system from anaerobic fungi. Enzyme Microbiology Technology, v. 21, p. 130-136, 1997. https://doi.org/10.1016/S01410229(96)00251-7

RUSSELL, J. B.; RYCHLIK, J. L. Factors that alter rumen microbial ecology. Science, v. 292, p. 11191122, 2001. https://doi.org/10.1126/science.1058830

RUIZ-LACAZ, R. et al. Microbiologia do rúmen e do biodigestor. In: RUIZ-LACAZ, R. Microbiologia zootécnica. São Paulo: Roca, p. 123-167, 1992. 
RUSSELL, J. B.; HINO, T. Regulation of lactate production in Streptococcus bovis: a spiraling effect that contributes to rumen acidosis. Journal Dairy Science, v. 68, p. 1712-1721, 1985. https://doi.org/10.3168/ids.S0022-0302(85)81017-1

SEAB - Secretaria deEnsino da Agricultura e do Abastecimento. Análise da Conjuntura Agropecuária. 2014.

STEWART, V. J. Nitrate respiration in relation to facultative metabolism in enterobacteria. Microbiological Reviews, v. 52, p.190-232, 1988.

STEWART, C. S. Plant-Animal and Microbial Interactions in Ruminant Fibre Degragation. In: Microorganisms in Ruminant Nutrition. Editado por PRINS, R. A., STEWART, C. S. DeBron Conference Centre, Dalfsen, The Netherlands. Nottingham University Press. Nottingham, 1994.

TKALCIC, S.; BROWN, C. A.; HARMON, B. G. Effects of diet on rumen proliferation and fecal shedding of Escherichia coli 0157:H7 in calves. Journal Food Protein, v. 63, p.1630-6, 2000. https://doi.org/10.4315/0362-028X-63.12.1630

TRINCI, A. P. J. Anaerobic Fungi: Their Distribution and Life Cycle. In: PRINS, R. A.; STEWART, C. S. (Ed.). Micro-organisms in Ruminant Nutrition. Dalfsen: Nottingham University Press, 1994.

WALLACE, R. J. Ruminal microbiology, biotechnology, and ruminant nutrition: progress and problems. Journal of Animal Science, v. 72, p. 2992-3003, 1994.

WALLACE, R. J.; NEWBOLD, C. J. Microbial feed additives for ruminants. In: Probiotics: Prospects of Use in Opportunistic Infections. Editado por FULLER, R.; HEIDT, P.; RUSCH, V.; VAN DER WAIJ, D. Germany: Institute for Microbiology and Biochemistry, p. 101-125, 1995. https://doi.org/10.2527/1994.72112992x

ZHAO, S.; WANG, J.; ZHENG, N.; BU D.; SUN, P.; YU, Z. Reducing microbial ureolytic activity in the rumen by immunization against urease therein. BMC Veterinary Research, v.11, n. 94, p. 4-8, 2015. https://doi.org/10.1186/s12917-015-0409-6

ZIMMER, A. H.; EUCLIDES, V. P. B. Importância das pastagens para o futuro da pecuária de corte no Brasil. In: SIMPÓSIO DE FORRAGICULTURA E PASTAGEM, 1, 2000, Lavras. Anais... Lavras: Universidade Federal de Lavras, 2000. p.1-49. 